Disclosure of Interests: Vitoria Elias: None declared, Zelita Queiroz: None declared, Sergio Catanozi: None declared, Antonio Santos Filho: None declared, Sandra Fernezlian: None declared, Ana Paula Velosa: None declared, Percival D. Sampaio-Barros Speakers bureau: Actelion, Boehringer Ingelheim, Abbvie, Lilly, Novartis, Consultant of: Abbvie, Bayer, Boehringer Ingelheim, Lilly, Novartis, Pfizer, Vera Capelozzi: None declared, Walcy Teodoro: None declared

DOI: 10.1136/annrheumdis-2021-eular.3663

\section{POS0433 CAN INTERLEUKIN 33 (IL-33) BE CONSIDERED A VALUABLE BIOMARKER IN THE EARLY STAGES OF SYSTEMIC SCLEROSIS? ANALYSIS OF A MONOCENTRIC COHORT}

C. Angelelli ${ }^{1}$, K. Stefanantoni ${ }^{1}$, M. Cadar ${ }^{1}$, G. Pellegrino ${ }^{1}$, F. Conti ${ }^{1}$, V. Riccieri ${ }^{1}$. ${ }^{1}$ Sapienza University of Rome, Scienze cliniche internistiche, anestesiologiche e cardiovascolari, Roma, Italy

Background: The ScS approach has changed considerably in recent years especially concerning the very early diagnosis of the disease (VEDOSS) at the time when the patient is still in an undifferentiated form (UCTD) at risk of developing SSc $(1,2)$. Of great value are different clinical, instrumental and laboratory findings, such as specific autoantibodies and Nailfold VideoCapillaroscopy (NVC), able to identify those cases progressing into overt SSc. IL-33 cytokine is known to exert pro-fibrotic effects through its membrane receptor ST2 on immune cells and myofibroblasts and recent studies suggest that it can be released following endothelial cell activation at the onset of SSc $(3,4)$

Objectives: Our aim has been to evaluate IL-33 serum levels in a monocentric cohort of VEDOSS patients, looking for the possible association with clinical phenotype and disease progression, focusing on the microvascular capillaroscopic changes.

Methods: Fourty-seven VEDOSS patients underwent a complete clinical, instrumental and laboratory evaluation, including NVC and specific SSc autoantibodies. At baseline serum IL-33 levels were measured using an ELISA assay. In 32 of them we also had a second serum sample at a follow-up time of at least 24 months (range 24 to 96 months).

Results: During the follow-up time, 17 patients were subsequently reclassified as having ScS whereas 30 remained VEDOSS. The "progressor" subjects positively correlated with the presence of anti-Topoisomerase I antibodies ( $p>0,004)$. IL-33 concentrations had a median value of $427.2 \mathrm{pg} /$ $\mathrm{ml}$ (IQR $967.9 \mathrm{pg} / \mathrm{ml}$ ) at baseline and of $130.4 \mathrm{pg} / \mathrm{ml}$ (IQR $399 \mathrm{pg} / \mathrm{ml}$ ) at the follow up, showing a statistically significant difference independently from the progression of the disease $(p=0.03)$. Besides significantly higher levels were detected in those patients with more severe NVC changes, defined as "active" pattern $(\mathrm{p}<0.05)$. Among the 47 VEDOSS patients, 12 started some kind of vascular therapy. In these patients serum IL-33 concentrations significantly lowered during the follow-up respect to those without any treatment $(p<0.03)$

Conclusion: The analysis of our data confirms previous report (5) on higher IL-33 serum levels in the very early stages of UCTD patients at risk for SSc, regardless of their progression in established SSc, although related to more severe microvascular NVC involvement. The lowering of IL-33 serum levels that we detected in the follow up of our patients, may be linked to the well-known endothelial changes during the progression of the SSc and seems also to be partially affected by treatments. Investigation on a greater number of patients are needed to better understand our findings.

REFERENCES:

[1] J. Avouac et al. Ann Rheum Dis 2011

[2] G Valentini et al. Clin Exp Med 2017

[3] Manetti M, et al. Ann Rheum Dis 2010

[4] Terras S et al. Ann Rheum Dis 2013

[5] Vettori S, et al. J Clin Immunol 2014

Disclosure of Interests: None declared

DOI: 10.1136/annrheumdis-2021-eular.4196

\section{Basic and translational pain science}

POS0434

CLINICAL UTILITY OF SCREENING TOOLS IN REFERRAL OF PATIENTS WITH HAND ARTHRALGIA TO RHEUMATOLOGISTS

G. Figueroa-Parra ${ }^{1}$, D. Vega-Morales ${ }^{1}$, P. Herrera-Sandate ${ }^{1}$, J. A. Esquivel Valerio $^{1}$, B. R. Vázquez Fuentes ${ }^{1}$, M. A. Garza Elizondo ${ }^{1}$, Y. G. Ordoñez Azuara $^{2}$, R. F. Gutierrez-Herrera ${ }^{2}$, D. Á. Galarza-Delgado ${ }^{1} .{ }^{1}$ Hospital
Universitario Dr. José Eleuterio González, Rheumatology Service, Monterrey, Mexico; ${ }^{2}$ Hospital Universitario Dr. José Eleuterio González, Family Medicine Department, Monterrey, Mexico

Background: Clinically Suspect Arthralgia (CSA) was defined by European League Against Rheumatism to identify a combination of clinical features that best characterise patients with arthralgia who are at risk of progression to rheumatoid arthritis (RA) (1). A specificity $>90 \%$ is obtained with the presence of $\geq 4$ parameters. Another clinical feature useful to identify patients at risk is the squeeze test (ST). Recently, we have identified the necessary strength to screen the patient with arthralgia through ST, with a median squeeze force of $3 \mathrm{~kg}$ and $2.78 \mathrm{~kg}$ to evoke pain in the right and left hand of the RA patient, respectively (2). Primary care physicians (PCP), the first contact of patients at risk, could benefit from these screening tools, prompting early referral, diagnosis, and treatment of these individuals. Objectives: To identify the clinical utility of CSA and ST in the referral of patients with hand arthralgia from PCP to rheumatologists.

Methods: We conducted a cohort study from October 2018 to December 2020 in 110 patients who attended a Family Medicine clinic at University Hospital "Dr. Jose Eleuterio Gonzalez" in Monterrey, Mexico. We recruited patients with hand arthralgia with no history of previous trauma or autoimmune rheumatic diseases. A questionnaire assessing CSA criteria was employed, and an ST maneuver was performed through an automated compressor with quantitative measures of applied force. Patients were grouped based on referral to Rheumatology consultation and variables categorized according to clinically relevant thresholds. Chi square test was performed in categorical variables, t-student test was performed in normal, continuous variables and Spearman's rho correlation was utilized between CSA number of criteria and quantitative ST force using SPSS v25.

Results: Out of 110 patients, 49 (44.5\%) were referred to a rheumatologist. A non-significant association was found across assessed variables in referred and non-referred patients as seen in Table 1. Spearman's rho found a moderate correlation between the number of CSA criteria and quantitative force in right $(r=-.445)$ and left $(r=-.382)$ hand as seen in Figure 1. Evaluation of CSA cutoffs other than $\geq 4$ did not yield a significant association in referral of patients to the rheumatologist (data not shown)

Conclusion: The clinical utility of CSA criteria and ST in referral of patients with hand arthralgia from PCP to rheumatologists is currently limited. More research is needed to elucidate the clinical utility of these screening tools.

\section{REFERENCES:}

[1] van Steenbergen HW, et al. EULAR definition of arthralgia suspicious for progression to rheumatoid arthritis. Ann Rheum Dis. 2017;76(3):491-496.

[2] Vega-Morales D, et al. Automated squeeze test (Gaenslen's manoeuvre) to identify patients with arthralgia suspicious for progression to RA: improving time delay to rheumatology consultation. Ann Rheum Dis. 2017;76(10):e40.

Table 1. Demographic characteristics and clinical performance of CSA and ST in referral of patients with hand arthralgia from PCP to rheumatologists.

\begin{tabular}{lccc}
\hline & $\begin{array}{c}\text { Referred patients, } \\
\mathbf{n}=\mathbf{4 9}\end{array}$ & $\begin{array}{c}\text { Non-referred patients, } \\
\mathbf{n}=\mathbf{6 1}\end{array}$ & $p$ \\
\hline Female, $\mathrm{n}(\%)$ & $40(81.6)$ & $50(82.0)$ & 0.964 \\
Age in years, mean \pm SD & $46.76 \pm 14.43$ & $52.05 \pm 15.00$ & 0.064 \\
Patients with $\geq 4$ CSA criteria, $\mathrm{n}(\%)$ & $23(46.9)$ & $19(31.1)$ & 0.090 \\
Right hand positive ST patients, $\mathrm{n}(\%)$ & $21(42.9)$ & $22(36.1)$ & 0.468 \\
Left hand positive ST patients, $\mathrm{n}(\%)$ & $26(53.1)$ & $28(45.9)$ & 0.455 \\
Force in right hand ST, mean kg \pm SD & $4.19 \pm 2.92$ & $3.86 \pm 3.07$ & 0.571 \\
Force in left hand ST, mean kg \pm SD & $4.25 \pm 3.04$ & $3.54 \pm 2.74$ & 0.198 \\
\hline
\end{tabular}

CSA, Clinically Suspect Arthralgia; ST, Squeeze Test; SD, Standard Deviation.

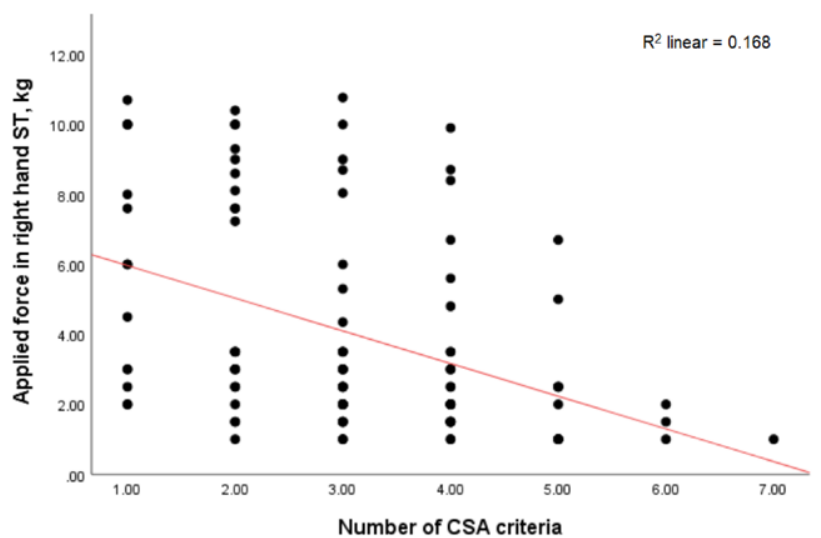

Figure 1. Scatter plot showing a moderate correlation between the number of CSA criteria and applied force in the right hand ST in $\mathrm{kg}$, Spearman's rho $=-.445$.

Disclosure of Interests: None declared

DOI: 10.1136/annrheumdis-2021-eular.3754 